\title{
Some proposed emendations to larval morphology terminology
}

\author{
Peter S. Cranston \\ Evolution, Ecology and Genetics, Research School of Biology, The Australian National University, \\ Canberra, 0200, Australia \\ E-mail:pscranston@gmail.com
}

Despite the publication of an intended consistent terminology for the morphology of chironomid larvae (Sæther 1980) as applied in Wiederholm et al (1983), two areas have remained controversial, with inconsistently applied terminology. The first and perhaps most confusing concerns the dorsal head sclerites, the second, the terminology of the mandibular teeth of Tanypodinae. In preparation for the $2^{\text {nd }}$ edition of the Holarctic larval keys, I have attempted to reconcile differing approaches to naming the parts of these larval cephalic structures.

I started with recognising that we need hypotheses that (a) cover putative homology across insects as a whole, (b) conform across all 'Nematocera' with complete head capsules, and (c) can be implemented across all Chironomidae. Of course homologies are hypotheses derived from data (observations) and thus are not 'right' or 'wrong', only tested / refuted by further data. All names of anatomical (morphological) parts, purportedly 'neutral' or not, are hypotheses of 'sameness' = homology. Thus we should use names for parts that clearly hypothesise homology - especially when they are available and have meaning outside the subfamily Chironominae. Equally evident is that we cannot and should not have a separate morphological terminology from closely related groups and our use in chironomids should not be at variance with standard entomological works such as Snodgrass (1935) and Torre-Bueno (1989), and modern textbooks (e.g. Gullan \& Cranston 2010).

First I sought to understand the dorsal head, which proves variation so useful in taxon-discrimination in, for example, the Chironominae (e.g. Goeldichironomus in Reiss, 1974, Endochironomus group in Grodhaus, 1987, and Kiefferulus in Cranston, 2007) (Fig. 1). The terminology applied previously to the various parts has been a mixture of homology and 'neutral' terms, creating some confusion and inconsistency in their application. Starting from basic insect head morphology, it should be noted that there is no 1:1 relationship between sclerotised parts of heads and primitive segmentation. Although there is thus a certain arbitrariness in defining head parts, never-the-less regions of the head across all insects can be recognised by sutures these parts are the frons, clypeus, labrum in posterior-anterior order. There are no other recognised regions in any group that are available for insertion in this sequence.

At least across Nematocera, but seemingly much more widely, there are defining cephalic setae and sutures (differentiated borders) associated with each part. Thus S1 and S2, the labral setae, belong on the labrum, S3, the clypeal setae, on the clypeus, and S4 and S5, the frontal setae, on the frons. There is no need for the term frontal apotome - 'apotome' is either redundant or misleading. In Torre-Bueno (1989) its use is ascribed only to the Chironomidae. The frontal apotome is the frons.

Starting posteriorly, cephalic setae S4 and S5 lie on the frons, a uniform sclerite that fills the area completely, with the exception of a thinned area, the fenestra, in certain Chironomini (fen in Fig. 1). The frons lacks membranous parts that otherwise would allow flexibility and therefore it is rigid. It is bounded posteriorly and laterally by the ecdysial lines along which the cuticle opens at ecdysis (emergence of the next stage). Anteriorly often is a boundary of less sclerotised cuticle, anterior to which lies the head region called the clypeus (clyp, delimited in Figs 1A, B, E by a red boundary line). This region includes membranous and denser cuticle - the thicker median area, termed a sclerite, is of variable shape and size but rarely fills the entire clypeal area. The S3 (clypeal setae) can (rarely) lie on the clypeal sclerite, but are located at the postero-lateral corner of the clypeus, usually on membranous cuticle that allows increased flexion. The anterior margin of the clypeus also is membranous, abutting the labral sclerite (lab) which varies in degree of subdivision. The S1 labral setae often, but not always, lie on the labral sclerite. Laterally the labrum bears the S2 labral setae. Here there may be up to 3 pairs of lateral sclerites which may be complete, partially or totally fragmented, or not discernible from the background. These visible lateral sclerites may be distinctive and numbered 1-3 as in Fig. 2, but more usually the structures are partially or completely fused with indistinct subdivision (see variation in this development in Fig. 1, especially in unlabelled G, H, I). Anteriorly the labrum bears the SI - SIV setae, labral chaetae etc and terminates antero-laterally at the tormal bar. 

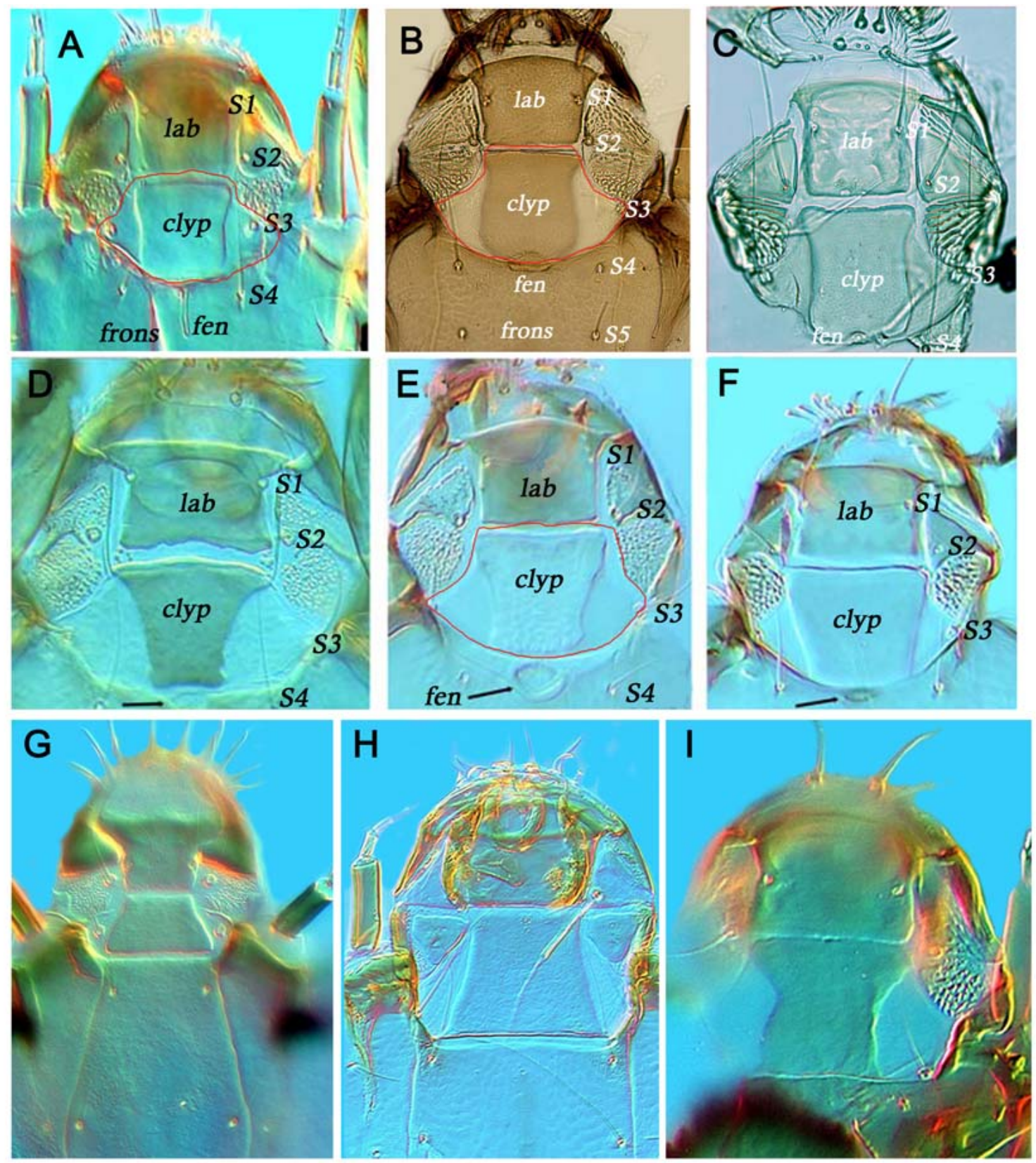

Figure 1. Dorsal larval heads of Chironomini. A. Dicrotendipes septemmaculatus (Becker); B. Glyptotendipes paripes Edwards); C. Glyptotendipes 'sp. E' Epler 2001; D. Kiefferulus longilobus (Kieffer); E. Kiefferulus calligaster Kieffer; F. Kiefferulus barbatitarsis Kieffer; G. Endotribelos sp.; H. Goeldichironomus carus (Townes); I. Goeldichironomus sp.

This unit comprising the frons plus clypeus plus labrum is 'split off' as a single structure at ecdysis - it is completely bounded by weak ecdysial lines. The genae are not part of this, and there are no genal elements on the dorsal head. This is the basic pattern against which variants can be defined. Thus fusion of the clypeus with frons, with S3-5 on a single unit - is a frontoclypeus. Fusion of frontoclypeus with labrum is frontoclypeolabrum, bearing all S setae (1-5). Rarely (uniquely) there is a fusion of clypeus and labrum to form a clypeolabrum (Kribiodorum). The anterior margin of the frons or frontoclypeus may be straight, concave or convex. The frons, whether separate from the clypeus or fused, can have a fenestra (interiorly thinned cuticle). We do not know if 'pits' are homologous to oval fenestra, but certainly 'pits' do not cooccur with fenestra and are not 'pits' (depressions in the external cuticle).

The test of this hypothesis is its applicability in all Chironominae, and hopefully beyond. An issue is that in taxonomic studies dorsal heads are not always illustrated. In many cases this seems to be because of apparent uniformity, for example in Tanypodinae, the Harnischia cpx and many Tanytarsiini. However, all 


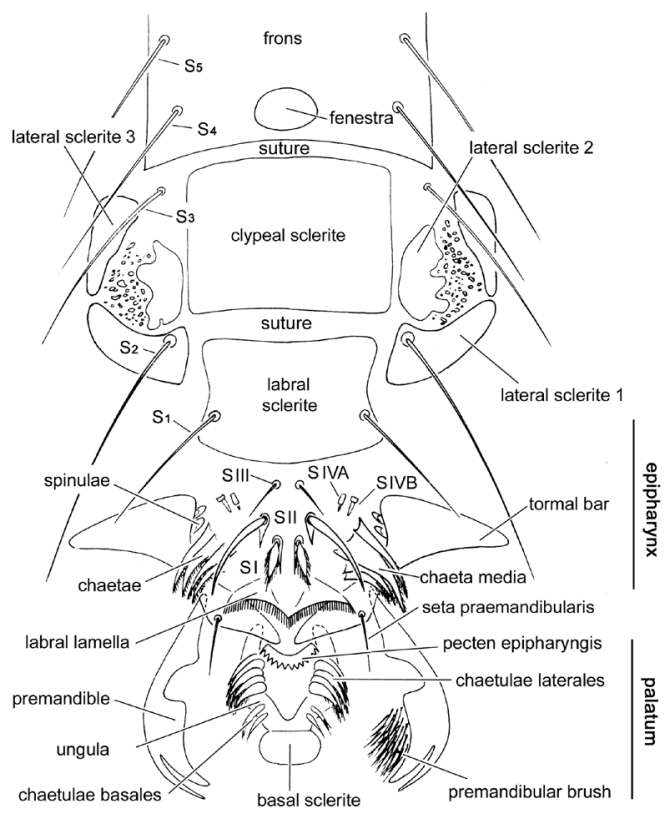

Figure 2. Labelled schematic for dorsal larval head, Chironominae.

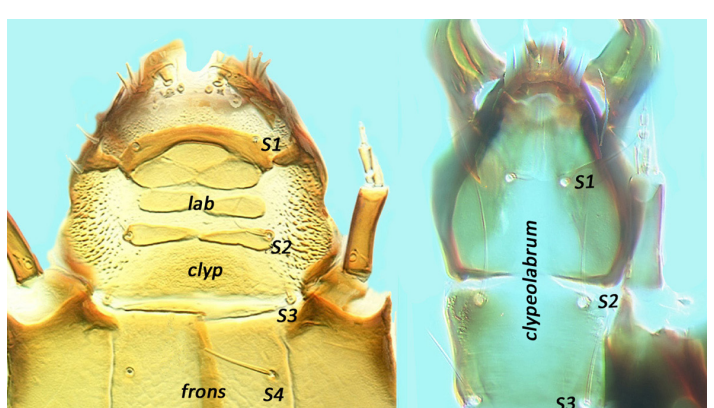

Figure 3. Dorsal larval heads of Orthocladiinae. A. Brillia, B. Elpiscladius

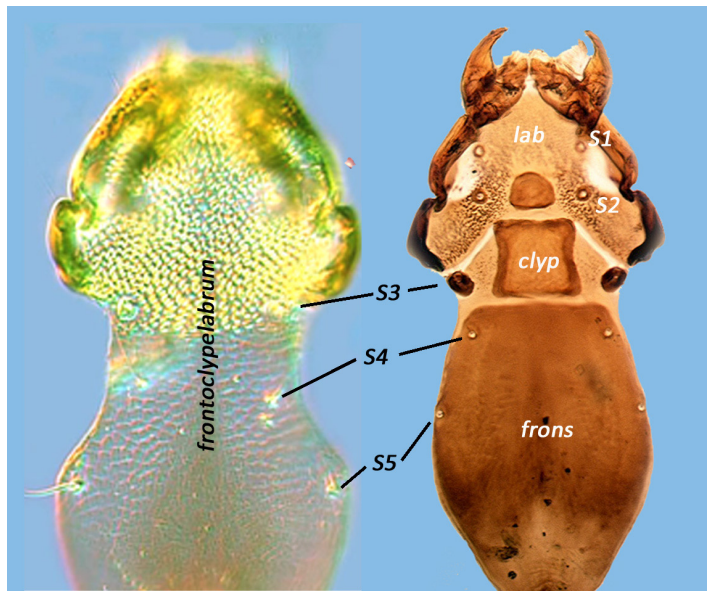

Figure 4. Dorsal larval heads of Telmatogetoninae. A. Telmatogeton, B. Thalassomyia

images in the Lucid on-line key (http://keys.lucidcentral.org/keys/v3/Chironomidae/) have been viewed. The morphology of Glyptotendipes, which include the greatest variation and demonstrate most complexity, was discussed with Michael Heyn.

Since the scheme as labelled in Figures 1 and 2 'worked' even for problematic taxa, I verified (and sometimes emended) the generic diagnoses for the revision of the Holarctic Chironomidae for which the feature is applicable. Difficulties were encountered only in the strange arrangement in Kribiodorum but I could locate no description or figure that could be reconciled with the 'divided labral sclerite 1 and 2' of Sæther's glossary (1980: fig. 62). However the situation occurs only in Xenochironomus - but I don't believe that this anomalous dorsal head structure damages the proposed scheme. The caricature dorsal head, as labelled in Figure 2, thus appears applicable across all Chironominae

The dorsal heads of Orthocladiinae generally follow Hirvenoja's (1973) figures, including cephalic setal terminology and locations - except in Brillia group in which there are interesting variations (Fig. 3). All can be incorporated into the new naming scheme, although the situation in South African Elpiscladius (Fig. 3B) is unusual. In contrast to the original interpretation (Cranston 2008), now I interpret Elpiscladius as showing a fused clypeo-labrum in which there is secondary near division into anterior section with S1 seta, and posterior, section with S2 and S3 (the separate frons, bearing S4 and S5, is omitted from the image).

The distinctive variation in dorsal head morphology in the Telmatogetoninae was recognised by text and drawings in Cranston (1983). Terminology can be emended easily to follow the new system, as labelled in Figure 4.

The most misleading interpretation concerned the dorsal head of the Tanypodinae, but fortunately the feature has been little used in identification. The problem is misinterpretation of the cephalic S setae, including by Müh (1985) who mistakenly termed and labelled the frontal seta S5 as S4 (no S5 is labelled or mentioned in Müh). This, or a similar error, may explain the strange statement "clypeus covering almost entire head" (Fittkau and Roback, 1983: p. 33). Actually it is the frons that extends nearly entirely to cover the dorsal head, with S1, 2 and 3 on poorly-differentiated, far-anterior, clypeo-labral microsclerites. 
The proposed scheme thus seems validated across the family. In implementation it is important to recognise Gail Grodhaus who interpreted the S3 / clypeus issue (Grodhaus. 1987) as a problem of logic. Of course, Gail worked also with mosquito larvae, so his outgroup was appropriate.

Turning to the tanypod mandible: Fittkau \& Roback (1983) used a different terminology for describing the various associated teeth. However, the terms 'apical tooth' and 'inner teeth' can and should be used as in other subfamilies. If we recognise the widespread term 'mola' for the inner mandibular margin basal to the insertion of the seta subdentalis, then distal projections of the mola should not treated as 'inner' teeth, as so termed in all other subfamilies, but molar projections (see Fig. 5). The inner teeth of the tanypod mandible, when present, should be restricted to those generally small teeth that lie distally between the mola / site of seta subdentalis insertion and the base of the strong apical tooth.

\section{Acknowledgements}

I thank particularly John Epler for engaging discussions on chironomid larval morphology, and Mike Heyn for correspondence concerning the dorsal heads of Glyptotendipes.

\section{References}

Cranston, P.S. 1983. Keys and diagnoses of the larvae of the subfamily Telmatogetoninae (Diptera, Chironomidae) of the Holarctic Region. - Entomologica Scandinavica Supplement 19: 17-22.

Cranston, P.S. 2007. The Chironomidae larvae associated with the tsunami-impacted waterbodies of the coastal plain of south-western Thailand. - Bulletin of the Raffles Museum 55: 231-244.

Cranston, P.S. 2008. Phylogeny predicts larval biology in a wood-mining chironomid (Diptera: Chironomidae). - African Entomology 16: 1-6

Fittkau, E.J. and Roback, S.S. 1983. The larvae of Tanypodinae (Diptera: Chironomidae) of the Holarctic region. Keys and diagnoses. - Entomologica scandinavica Supplement 19: 33-110.

Grodhaus, G. 1987. Endochironomus Kieffer, Tribelos Townes, Synendotendipes, n. gen., and Endotribelos, n. gen. (Diptera: Chironomidae) of the Nearctic region. - Journal of the Kansas Entomological Society 60: 167-247.

Gullan, P.J. and Cranston. P.S. 2010. Insects: An Outline of Entomology, 4th edition. 565 pp., Wiley-Blackwell Science, Oxford.

Hirvenoja, M. 1973. Revision der Gattung Cricotopus van der Wulp und ihrer Verwandten (Diptera: Chironomidae). - Annales Zoologici Fennici 10: 1-363.

Müh, C. 1985. Kopfmorphologie der Larven der Tanypodinae (Chironomidae: Diptera) am Beispiel von Macropelopia nebulosa (Meigen). - Zoologische Jahrbücher, Anatomie 113: 331-62.

Reiss, F. 1974. Die in stehenden Gewässern der Neotropis verbreitete Chironomiden-gattung Goeldichironomus Fittkau (Diptera, Insecta). - Studies on the Neotropical Fauna 9: 95-122.

Sæther, O.A. 1980. Glossary of chironomid morphology terminology (Chironomidae: Diptera). - Entomologica scandinavica Supplement 15: 1-51.

Snodgrass R.E. 1935. Principles of Insect Morphology. New York: McGraw-Hill.

Torre-Bueno, J.R. de la. 1989. The Torre-Bueno Glossary of Entomology. $2^{\text {nd }}$ edn. The New York Entomological Society in cooperation with the American Museum of Natural History, New York.

Wiederholm, T. (ed.) 1983. Chironomidae of the Holarctic region. Keys and Diagnoses. Part 1. Larvae. - Entomologica Scandinavica Supplement 19: 1-457. 